\section{EMBRYRIDDLE}

Aeronautical University

SCHOLARLY COMMONS
Journal of Aviation/Aerospace

Education \& Research

Volume 17

Number 3 JAAER Spring 2008

Article 7

Spring 2008

\title{
Modeling the Balance between Standardization and Innovation in a Flight School
}

\author{
Michael J. Wetmore \\ Chien-tsung Lu \\ Philip Bos
}

Follow this and additional works at: https://commons.erau.edu/jaaer

\section{Scholarly Commons Citation}

Wetmore, M. J., Lu, C., \& Bos, P. (2008). Modeling the Balance between Standardization and Innovation in a Flight School. Journal of Aviation/Aerospace Education \& Research, 17(3). https://doi.org/10.15394/ jaaer.2008.1457

This Article is brought to you for free and open access by the Journals at Scholarly Commons. It has been accepted for inclusion in Journal of Aviation/Aerospace Education \& Research by an authorized administrator of Scholarly Commons. For more information, please contact commons@erau.edu. 


\title{
MODELING THE BALANCE BETWEEN STANDARDIZATION AND INNOVATION IN A FLIGHT SCHOOL
}

\author{
Michael J. Wetmore, Chien-tsung Lu and Philip Bos
}

\begin{abstract}
The purpose of this paper is to examine the relationship between standardization and innovation in a university flight training program. Quantitative and qualitative data were generated for this investigation by a human subjects study involving senior students in a collegiate pro-pilot program. The survey provided the following lack of innovation indicators: (a) failure to achieve program goals; (b) loss of flight training students to competitor flight schools; and (c) substandard flight training efficiency. A model describing the balance between standardization and innovation is proposed: (a) too much standardization mires a flight school in stagnation; (b) too little standardization results in a lack of professionalism; (c) too much innovation creates a chaotic training program; (d) too little innovation produces unmotivated students; and (e) too many resistors to change at the management level results in stagnation and a lack of innovation. Flight schools that can achieve a good balance between standardization and innovation would enjoy two main benefits: (a) positive and imaginative learning atmosphere that encourages instructors to train their students above and beyond the minimum standards without sacrificing safety; and (b) exciting and creative training environment that motivates students to achieve their goals without sacrificing professionalism.
\end{abstract}

\begin{abstract}
Introduction
Purpose

With the advent of new pilot training initiatives such as the FAA/Industry Training Standards (FITS) program and the introduction of Technically Advanced Aircraft (TAA), many flight schools in the flight training industry are faced with the challenge of maintaining equilibrium between standardization and innovation. Therefore, the purpose of this study is to investigate the balance between standardization and innovation in a collegiate aviation flight training program. The objective of this research is to create a model of the relationship between the values that promote creativity and the norms that induce stagnation in the flight training environment. We hope that an understanding of this standardization and innovation balance model might be beneficial to any aviation educators or flight school personnel trying to implement changes in their flight training programs.
\end{abstract}

\section{Background}

Standardization is essential to aviation safety and thus, to a great extent, is considered to be an advantageous and needed mechanism in flight schools. Collegiate flight training programs need standardization to turn out safe, professional pilots similar to airline operation. Standardization is what keeps a flight school from degenerating into chaos. Innovation is also generally considered to be beneficial. Without the creative and imaginative forces that drive innovation, it would be difficult for a flight school to adapt to new technology and to develop new training techniques. Innovation is needed in order to train pilots above and beyond the minimum standards. However, embracing standardization and innovation is not a pedagogical priority for some flight training institutes due to a variety of reasons.

Research Problem

The research problem can be characterized as follows: Collegiate flight schools may have an imbalance 
between standardization and innovation which stifles the learning principles of effect and intensity. This stifling of innovation results in a flight school management that is mired in stagnation and a flight instructor staff that is reticent to be either imaginative or creative during flight training.

Data for this paper came from a human subjects study in a Part 141 collegiate aviation program. This investigation targeted the senior pro-pilot class because it was felt that they would have the best perspective on flight training issues in the flight school. This unique perspective is derived from the fact that they have had four years of experience in trying to achieve their personal and departmental goals in the flight training program. This study generated both quantitative and qualitative data regarding standardization and innovation. The quantitative data came from a detailed examination of the student pilot logbooks. The qualitative data were derived from student pilot comments regarding the flight school.

\section{Research Questions}

To investigate the research problem, research questions were developed regarding flight training in a collegiate aviation program. These research questions are shown below:

1. What are some of the indications that a flight school lacks innovation?

2. Who are the main resistors to innovation in a flight school?

3. What are the characteristics of a flight school with too much or too little standardization?

4. What are the characteristics of a flight school with too much or too little innovation?

5. What are the benefits of a good balance between standardization and innovation in a flight school?

\section{Concurrent Lines of Investigation}

This paper is one of several studies generated by a larger, comprehensive research project utilizing National Transportation Safety Board (NTSB) Factual Report data and human subject surveys. This research project is concerned with aviation safety, Crew Resource Management (CRM), Aeronautical Decision-Making (ADM), and flight training issues. A brief summary of the main conclusions from these concurrent lines of investigation are pertinent to this paper: (a) non-flight related human error is the most significant direct hazard affecting FAR Part 121 airline safety (Lu, Przetak, \& Wetmore, 2005); (b) hazardous attitudes have a detrimental effect on certain CRM skills such as risk-taking, decision-making, pilot error, and resource utilization (Wetmore \& $\mathrm{Lu}$, in press); (c) pilot age, young or old, has no measurable effect on ADM and CRM skills (Wetmore \& Lu, 2005a); (d) increased levels of pilot certification and flight experience significantly reduce displayed hazardous attitudes (Wetmore \& Lu, 2005b); (e) certain pedagogical paradigms can have either ameliorating or exacerbating effects on ADM skills in the flight training environment (Wetmore, Lu \& Caldwell, in-press); and (f) certain interpersonal conflict management styles can be either beneficial or harmful when applied to student pilots with hazardous attitudes (Wetmore, Lu \& Bos, 2006).

\section{Method}

\section{Participants}

The target population of this study was the senior class of a collegiate aviation professional pilot program. Enrollment data were used to identify the 36 members of this senior class. All 36 senior students were invited to participate. Of these, 33 students (92\%) agreed to participate and completed the survey instruments. With a sample of 33 and a population of 36 , the survey results have a confidence interval of $\pm 6.5 \%$ at the $99 \%$ confidence level.

Participation in the study was completely voluntary and anonymous. The identity of the participants cannot be connected with the responses to the survey. The participants were not compensated in any way and were free to withdraw from the study at any time.

Procedure

The study participants were given a single-stage survey (Creswell, 2003) to complete that consisted of four sections: (a) general information such as total time, dual time, Pilot In Command (PIC) time, number of weeks in the program, and details about the types and numbers of certificates and ratings earned; (b) flight training program questions concerning such subjects as flight instruction, aircraft, scheduling, maintenance, finances, academics, advisement, and flight school culture; (c) blank sheet of paper entitled "comments"; and (d) spreadsheet for the recording of logbook information such as total flight time versus calendar time, flight training delays, stage-checks, and check-rides.

This investigation utilizes the quantitative logbook data and the qualitative comments generated by the survey as they relate to standardization and innovation. The majority of the participants ( $97 \%$ ) contributed comments to the survey.

Validity

Internal validity (Wiersma \& Jurs, 2005) for this study is indicated by a $92 \%$ response rate and a confidence interval of $\pm 6.5 \%$ at the $99 \%$ confidence level. The 
researchers did not survey other flight schools, thus, it is not known if this study has external validity.

\section{Reliability}

To establish internal reliability, the researchers used consistent methods of data collection and agreed upon the analysis results and interpretations (Wiersma \& Jurs, 2005). Because the researchers did not include any other flight schools in the study, it is not known if this investigation has external reliability.

\section{Limitations}

The main limitation of this investigation is the narrow focus. This study sampled one class of pro-pilot students in a collegiate aviation program. A broader survey that included other classes might reveal how flight student attitudes towards the program have evolved as they progressed through the curriculum. A broader survey of other collegiate aviation programs would be required to determine if the results of this study are applicable to the collegiate flight training industry as a whole.

Despite these limitations, this study should have some value for the aviation education community. Other flight training professionals tasked with operating collegiate flight schools may be contending with similar standardization and innovation challenges. Future studies involving a collaborative effort among several university aviation programs examining the balance between standardization and innovation would not only help establish external validity and reliability, but could also yield significantly beneficial results for the collegiate flight training industry.

\section{Lack of Innovation Indicators}

Failure to achieve program goals. Organizations that are mired in stagnation share certain characteristics. Those that do not adapt to the marketplace often fail to meet internal goals and objectives (Tushman \& O'Reilly, 2002). The aviation program in this study publishes a recommended schedule of study that sets forth a goal for students to obtain their commercial pilot certificate (CPC) by the end of their junior year. Less than half (39.4\%) of the aviation students in this study met that goal (Table 1). An aviation student cannot graduate from this aviation program at the end of their senior year without earning their CPC. Slightly more than half (57.6\%) of the aviation students met this graduation requirement. To summarize, the majority of the aviation students failed to meet the recommended program flight training goals and nearly half of those students failed to meet those goals in order to graduate on time.

Loss of aviation students to competitors. Without innovation, organizations often lose their competitive standing in their respective marketplace (Kotter, 1996; Tushman \& O'Reilly, 2002). The aviation program in this study has certain admission policies designed to accommodate the needs of transfer students. These policies are designed to encourage students to enroll in the aviation program by offering credit for previously earned pilot certificates and ratings. These policies affect the following categories of aviation students: (a) those students transferring from other schools; (b) those students already enrolled in the university and desiring to switch majors; and (c) those students already enrolled in aviation and desiring to switch specializations within the program.

Aviation students who are frustrated and/or dissatisfied with their flight training have discovered certain loopholes in these admission policies that they can exploit to their advantage. Knowledge of these loopholes is passed from student to student by word of mouth. The result is that the majority $(57.6 \%)$ of these aviation students has earned pilot certificates and/or ratings at competitor flight schools (Table 2). Of those students who met the recommended program goals (in Table 1) the vast majority $(84.6 \%)$ used pilot certificates and/or ratings from competitor flight schools to meet those goals. Only a small number (6.1\%) of students were able to flight train exclusively at the aviation school in this study and achieve the published program goals.

Substandard flight training efficiency. An unchanging organization will inevitably see a decline in their productivity and efficiency (Handy, 2002). If an aviation student were to perfectly follow the Part 141 flight training syllabus at the school in this study, they would earn three certificates and ratings while flying 190 hours in 96 weeks. Using these numbers a couple of flight training indexes can be established. These indexes can then be used to gauge the efficiency of the flight training program. The Flight Time Per Week Index (FTPWI) is found by dividing a student's total time by the number of weeks in the program. The "perfect" student would have a FTPWI of 2.0 or more. The Flight Time Per Certificate or rating Index (FTPCI) is found by dividing the student's total time by the number of certificates and ratings earned. The "perfect" student would have a FTPCI of 63 or less.

However, it is the rare student who can perfectly follow a Part 141 program. Therefore, to facilitate discussion purposes, the researchers set more realistic standards for the FTPWI at $\mathbf{2 . 5}$ hours or more and the FTPCI at $\mathbf{8 0}$ hours or less. With an average of 3.1 flight hours per week, the majority $(57.6 \%)$ of the aviation students in this study met the FTPWI index efficiency goal 
of 2.5 hours or more (Table 3). On the other hand, with an average of 99.6 flight hours per certificate or rating, the majority (66.7\%) did not meet the FTPCI index efficiency goal of 80 hours or less.

By flying an average of 3.1 hours per week, the aviation students in this study are making the required effort to meet the program's flight training goals (Table 4). However, it is taking them an average of $\mathbf{9 9 . 6}$ hours to earn each certificate up through the CPC. As a result, the students are over-flying the Part 141 program by an average of 108.8 hours per student pilot. Even if all of the students were to switch over to Part 61 rules, they would still be over-flying the program by an average of $\mathbf{4 8 . 8}$ hours per student pilot. This data suggests that systematic inefficiencies may have pervaded this flight training program.

\section{Innovation Resistors}

Management structure. The management structure at the aviation school in this study is fairly simple. At the bottom are about 30 to 40 flight instructors. Above the flight instructors in the middle management position are 4 to 5 supervisors who would be equivalent to stage check instructors or assistant chief flight instructors at other flight schools. The supervisors are overseen by the chief flight instructor. The chief is supervised by the department chair who reports to the college dean who in turn answers to the university president.

Innovation stiflers. The behaviors and attitudes of management can be one of the main forces that stifle innovation within an organization (Kanter, 2002). These stiflers can be apathetic towards innovation or openly resistant to change (Shapiro, 2003). They can also be creativity passion-killers (Dundon, 2002). In addition, these innovation resistors can take the form of power-hungry egomaniacs or trust-destroying snakes (Kotter, 1996).

The majority of study participants (66.7\%) made comments about the flight school supervisors that were negative in nature (Table 5). A smaller percentage (9.1\%) provided positive comments about the supervisors.

A list of innovation stifling characteristics from Kotter (1996), Tushman \& O'Reilly (2002), and Dundon (2002) is shown in Table 6. Opposite these attributes of innovation stiflers are selected comments from the study participants. It should be noted that this is a small sample of the total student comments regarding management. This table illustrates why management could be the main source of resistance to innovation in this flight training program.

\section{Discussion}

\section{Summary of Results}

The quantitative and qualitative data (Tables 1-6) can be summarized as follows: (a) majority of the students failed to meet the program goals; (b) majority of the students used competitor flight schools to earn some of their certificates and ratings; (c) majority of the students are overflying individual certificates and/or ratings; (d) majority of the students are over-flying the program as a whole; and (e) majority of the students are somewhat critical of the flight school management's job performance.

Standardization versus Innovation

Theory. Standardization of procedures as it relates to pilot training is generally considered to be a cornerstone of safety and professionalism (Jensen, 1995; Fallucco, 2002). Operational innovation is generally considered to be a vital component of an organization's continued success (Kotter, 1996; Tushman \& O'Reilly, 2002; Dundon, 2002). Standardization and innovation should be able to coexist in an aviation program as suggested by the FITS initiative promoted by the FAA, industry and academia (FAA, 2004b).

Practice. How do standardization and innovation relate to one another in flight training programs? The answer to this question may exist in the attitudes of the flight school management. The cultural norms and values promoted by management may not favor innovation. Organizations that are resistant to innovation may have too few advocates and incubators in the program and too many apathetics and resistors (Shapiro, 2003). This results in an organization with cultural norms and values that are opposed to innovation and view any changes with suspicion (Pottruck, 2002). One of the keys to implementing innovation is creating a culture where new ideas are greeted with openmindedness rather than skepticism (Kotter, 1996; Dundon, 2002). Facilitating an understanding of the relationship between standardization and innovation could be the dooropener that empowers a change in the program's culture (Bolton, 1979).

Flight School Standardization and Innovation Model

Balance of opposing forces. One way to conceptualize standardization and innovation in the flight training environment is to think of them as opposing forces that are at the opposite ends of a balance beam (Figure 1). Too much standardization may result in too little innovation. And, too much innovation may result in too little standardization.

Too much standardization. Kotter(1996) listed the characteristics for an over-managed and under-led company culture: (a) managers exhibit arrogance; (b) managers fail to recognize the value of the customers; and (c) managers actively stifle innovation. A review of the student comments in Table 6 shows that the aviation program in this study may be suffering from this type of culture. It is possible that a 
flight school can become over-managed and under-led due to an over-reliance upon standardization. This is evidenced by managers who blindly enforce policies and procedures. Their strategy for resolving conflicts with students is to practice avoidance by hiding behind the rules and regulations (Lulofs \& Cahn, 2000). Evaluations are no longer conducted for the benefit of the students (FAA, 1999). Learning how to fly is no longer fun and students look for other flight training options ( Table 2). Thus, too much standardization could result in a flight school that suffers from stagnation ( Figure 1).

Too little innovation. Tushman \& O'Reilly (2002) listed the cultural norms for an innovative company: (a) managers are supportive; (b) managers are tolerant of new ideas; (c) managers understand that people make mistakes; (d) managers foster feelings of mutual respect; and (e) managers are positive role models. The student comments in Table 6 are contrary to the cultural norms needed for an innovative organization. Too little innovation may result in students who lack motivation (Figure 1). This lack of student motivation is evidenced by a lack of progress (Table 1) and a lack of flight training efficiency (Tables 3 and 4).

Too little standardization. This study produced no evidence regarding what would happen when there is not enough standardization in the flight training environment. And, no relevant aviation studies were uncovered in the literature. For the purposes of our model (Figure 1), we infer that too little standardization would result in a lack of professionalism in the flight school.

Too much innovation. Again, this study gathered no data concerning the results of too much innovation in flight schools. In addition, we did not find any applicable aviation studies in the literature. We surmise that too much innovation would lead to a chaotic flight training environment where every instructor was doing his or her own thing leading to flight training safety concerns.

Resistors. Shapiro (2003) lists a variety of reasons why some people in an organization are resistant to innovation: (a) fear that the change will result in a loss of position or power; (b) failure to see the value of the change; and (c) a belief that change is inappropriate. Many of those opposed to innovation desire to preserve the status quo (Kotter, 1996). In the flight school standardization and innovation model ( Figure 1), the resistors are the ones who keep the balance beam from moving in any direction. For a program with too much or too little standardization and/or innovation, the resistors keep the flight school from coming into balance. On the other hand, as Shapiro pointed out, resistance is not necessarily harmful. In a flight school with a good balance between standardization and innovation, the resistors would keep the program from becoming unbalanced.

The perfect balance between standardization and innovation. There are two principles of learning: Effect and Intensity (FAA, 1999). Both effect and intensity could be essential to innovation in a flight school. The Principle of Effect states that a positive and fun environment promotes learning while the Principle of Intensity asserts that an exciting and interesting atmosphere promotes learning. The perfect balance between standardization and innovation (Figure 1) can have two main benefits for an aviation program due to the learning principles of effect and intensity: (a) the flight school has a positive and imaginative learning atmosphere that encourages instructors to train their students above and beyond the minimum standards without sacrificing safety; and (b) the flight school has an exciting and creative training environment that motivates students to achieve their goals without sacrificing professionalism.

\section{Conclusions}

Innovation Rut. Organizations mired in stagnation are characterized by the following innovative ruts as described by Dundon (2002): (a) loss of competitive edge; (b) outside opinion is extremely unwelcome; (c) managers hide behind rules and policies; (d) new ideas are crushed because of a "that's not the way we do it around here" mentality; (e) abundance of internal conflict and competition; and (f) organization cannot attract or retain good people. A perusal of Tables 1 to 6 suggests that the flight school in this study may be mired substantially by an over-dependence on standardization that discourages innovation.

The data suggests that the flight training program in this study may need a cultural transformation that encourages the introduction of innovative flight training techniques. This type of innovative culture is required if the program is going to meet the needs of the students in an era of evolving technological advancements in aviation. This cultural change can be accomplished by sorting out the advocates and resistors, building an enthusiastic and imaginative management coalition, and encouraging a flight school atmosphere that supports innovation.

Advocates versus Resisters. According to Shapiro's (2003) tipping point model of organizational change, in order for successful innovation to occur, the number of advocates and incubators has to be larger than the number of apathetics and resistors at the management level. The data in this study suggests that apathetics and resistors may outnumber the advocates and incubators in this aviation program (Table 5). Consequently, for a flight training program such as this to become more innovative, it has to 
build a management coalition that advocates and incubates innovative flight training approaches and ideas.

Building a management coalition. Kotter (1996)

listed three ingredients for building a management coalition that can advocate and incubate innovations: (a) find enthusiastic and imaginative people to be in the group; (b) create trust within the group; and (c) develop a common goal for the group to work towards. This type of management coalition, given the proper direction and motivation, could promote a proper balance between standardization and innovation at the flight school in this study (Figure 1).

Finding the right people can either involve motivating the current managers to become part of the innovation effort, or isolating them from the relevant chain of command, or removing them from the organization (Tushman \& O'Reilly, 2002). There are certain cultural norms by which management can create trust within an organization: (a) encourage people to be creative and imaginative; (b) do not punish those who make mistakes while trying to be innovative; (c) reduce internal competition; (d) discourage negativity; and (e) display zero tolerance for non-productive behavior (Pfeffer, 2002). Common goals are established by getting management to use intellectual democracy to agree upon a vision for the organization's future, defining a clear-cut strategy to achieve that vision, and delineating a mutually agreeable set of values under which the strategy will be implemented (Knowling, 2002).

Changing the flight school culture. Students, flight instructors and flight school managers have to be educated concerning the benefits of a good balance between standardization and innovation (Figure 1). The norms and values of the organizational culture have to be favorable towards new and innovative training techniques. Students should be aware that there are beneficial training exercises that are not necessarily listed on the Part 141 syllabus that can improve their piloting skills. Instructors should recognize that their flight students cannot learn anything new by monotonous repetition. Flight school managers must understand that their instructors cannot train student pilots above and beyond the minimum standards unless those instructors have the freedom to try new and innovative training techniques. The goal of this educational effort is to develop a flight school where the cultural values deliberately reward innovation and where the cultural norms actively discourage stagnation without sacrificing either safety or professionalism.t

Michael Wetmore is retired from the University of Central Missouri and practicing as a financial investor. His research interests include flight training, human factors, aviation psychology, and organizational administration.

Chien-tsung Lu is an assistant professor at the University of Central Missouri. His research interests currently focus on system safety management, aviation safety \& policy, and safety education.

Phillip Bos is an assistant professor at the University of Central Missouri. His research interests are aviation maintenance safety, airport management, and business administration. 


\section{References}

Bolton, R. (1979). People skills, how to assert yourself, listen to others, and resolve conflicts. New York: Simon \& Schuster.

Creswell, J. W. (2003). Research design: qualitative, quantitative, and mixed method approaches ( $2^{\text {nd }}$ ed.). Thousand Oaks, CA: Sage Publications, Inc.

Dundon, E. (2002). The seeds of innovation: cultivating the synergy that fosters new ideas. New York: American Management Association.

Fallucco, S. J. (2002). Aircraft command techniques. Burlington, VT: Ashgate Publishing Company.

Federal Aviation Administration. (1999). Aviation instructor's handbook (FAA-H-8083-9). Author.

Federal Aviation Administration. (2002a). Private pilot practical test standards (FAA-S-8081-14AS). Author.

Federal Aviation Administration. (2002b). Commercial pilot practical test standards (FAA-S-8081-12B). Author.

Federal Aviation Administration. (2004a). Airplane flying handbook (FAA-H-8083-3A). Author.

Federal Aviation Administration. (2004b). Federal aviation administration flight plan 2004-2008. Author.

Handy, C. (2002). Fleas and elephants. In F. Hesselbein, M. Goldsmith, \& I. Somerville (Eds.), Leading for innovation and organizing for results (pp. 23-30). New York: Jossey-Bass.

Jensen, R. S. (1995). Pilot judgment and crew resource management. Brookfield, VT: Ashgate Publishing Company.

Kanter, R. M. (2002). Creating the culture for innovation. In F. Hesselbein, M. Goldsmith, \& I. Somerville (Eds.), Leading for innovation and organizing for results (pp. 73-85). New York: Jossey-Bass.

Kotter, J. P. (1996). Leading change. Boston: Harvard Business School Press.

Knowling, R. E. (2002). Leading with vision, strategy, and values. In F. Hesselbein, M. Goldsmith, \& I. Somerville (Eds.), Leading for innovation and organizing for results (pp. 177-183). New York: Jossey-Bass.

Lu, C. T., Przetak, R., \& Wetmore, M. J. (2005). Discovering the non-flight hazards and suggesting a safety training model. International Journal of Applied Aviation Studies, 5(1), 135-151.

Lulofs, R. S., \& Cahn, D. D. (2000). Conflict from theory to action. Needham Heights, MA: Allyn \& Bacon.

Pfeffer, J. (2002). To build a culture of innovation, avoid conventional management wisdom. In F. Hesselbein, M. Goldsmith, \& I. Somerville (Eds.), Leading for innovation and organizing for results (pp. 95-104). New York: Jossey-Bass.

Pottruck, D. S. (2002). How company culture encourages innovation. In F. Hesselbein, M. Goldsmith, \& I. Somerville (Eds.), Leading for innovation and organizing for results (pp. 119-128). New York: Jossey-Bass.

Shapiro, A. S. (2003). Creating contagious commitment: applying the tipping point to organizational change. Hillsborough, NC: Strategy Perspective. 
Tushman, M. L., \& O'Reilly, C. A. (2002). Winning through innovation: a practical guide to leading organizational change and renewal. Boston: Harvard Business School Press.

Wetmore, M. J., \& Lu, C-t. (in press). The effects of hazardous attitudes on crew resource management skills. International Journal of Applied Aviation Studies.

Wetmore, M. J., Lu, C-t., \& Caldwell, W. (in-press). The effects of pedagogical paradigms on aviation students with hazardous attitudes. Journal of Aviation/Aerospace Education and Research.

Wetmore, M. J., \& Lu, C-t. (2005a). The effects of pilot age on aeronautical decision making and crew resource management skills. White paper. Central Missouri State University.

Wetmore, M. J., \& Lu, C-t. (2005b). Reducing hazardous attitudes: the effects of pilot certification and flight experience. White paper. Central Missouri State University.

Wetmore, M. J., Lu, C-t., \& Bos, P. (2006). Conflict management strategies related to hazardqus attitudes in the flight training environment. White paper. Central Missouri State University.

Wiersma, W., \& Jurs, S. G. (2005). Research methods in education ( $8^{\text {th }}$ ed.). Boston: Pearson Education, Inc. 


\section{Table 1: Flight Training Goals}

\section{Flight Training Goals}

Students who did not meet the program goal of earning their CPC by the end of their junior year

Students who met the program goal of earning their $\mathrm{CPC}$ by the end of their junior year

$$
\mathbf{N}=
$$

Students who did not meet graduation requirement of earning their CPC by the end of their senior year

Students who met the graduation requirement of earning their CPC by the end of their senior year

$$
\mathrm{N}=
$$

33
Percent (\%)

y

20

60.6

13

39.4

33

100
42.4

19

57.6

100

CPC: Commercial Pilot Certificate

Confidence interval: $\pm 6.5 \%$ at the $99 \%$ confidence level 
Table 2: Flight Training Competition

Flight Training Competition

Students who earned pilot certificates and/or ratings at competitor flight schools

Students who did not earn pilot certificates and/or ratings at competitor flight schools

$$
\mathrm{N}=
$$

Students who flight trained exclusively at the school in this study and met program goals

$$
\mathrm{N}=
$$

Of those students who met program goals (see Table 1), the number that used pilot certificates

19

14

33

2

3 and/or ratings from competitor flight schools to meet those program goals

$\mathrm{N}=\quad 13$

11

84.6

CPC: Commercial Pilot Certificate

Confidence interval: $\pm 6.5 \%$ at the $99 \%$ confidence level

11

84.6

57.6

42.4

100

6.1 
Table 3: Flight Training Efficiency by Index

Flight Training Efficiency by Index

Students who did not meet the flight training efficiency standard of more than 2.5 flights hours per week (FTPWI)

Students who met the flight training efficiency standard of more than 2.5 flights hours per week (FTPWI)
Frequenc Percent (\%)

y

14

42.4

19

57.6

$$
\mathbf{N}=
$$

33

100

Students who did not meet the flight training efficiency standard of less than 80 flight hours per certificate through the CPC (FTPCI)

Students who met the flight training efficiency standard of less than 80 flight hours per certificate through the CPC (FTPCI)

$$
\mathrm{N}=
$$

100

Aviation students who met both the flight hours per week (FTPCI) and the flight hours per certificate

(FTPWI) goals

$$
\mathbf{N}=
$$

33

FTPCI: Flight Training hours Per Certificate Index FTPWI: Flight Training hours Per Week Index CPC: Commercial Pilot Certificate

Confidence interval: $\pm 6.5 \%$ at the $99 \%$ confidence level 
Table 4: Flight Training Efficiency by Flight Hours

\begin{tabular}{|c|c|c|}
\hline \multirow[b]{2}{*}{ Flight Training Efficiency by Hours } & \multicolumn{2}{|c|}{$\begin{array}{c}\text { Flight Training Program } \\
\text { in this Study }\end{array}$} \\
\hline & Goal (hours) & $\begin{array}{l}\text { Student Pilot } \\
\text { Mean (hours) }\end{array}$ \\
\hline Number of flight hours per week (FTPWI). & 2.5 or more & 3.1 \\
\hline $\begin{array}{l}\text { Number of flight hours per certificate and } \\
\text { rating through the CPC (FTPCI). }\end{array}$ & 80 or less & 99.6 \\
\hline $\begin{array}{l}\text { Total flight hours required to earn all } \\
\text { certificates and ratings through the CPC } \\
\text { under Part } 141 \text { rules. }\end{array}$ & 190 & 298.8 \\
\hline Over-flying by students under Part 141 rules & & 108.8 \\
\hline $\begin{array}{l}\text { Total flight hours required to earn all } \\
\text { certificates and ratings through the CPC } \\
\text { under Part } 61 \text { rules. }\end{array}$ & 250 & 298.8 \\
\hline Over-flying by students under Part 61 rules & & 48.8 \\
\hline $\begin{array}{l}\text { FTPCI: Flight Training hours Per Certificate Index } \\
\text { FTPWI: Flight Training hours Per Week Index } \\
\text { CPC: Commercial Pilot Certificate } \\
\text { Confidence interval: } \pm 6.5 \% \text { at the } 99 \% \text { confidence level }\end{array}$ & & \\
\hline
\end{tabular}




\section{Table 5: Flight School Supervisor Comments}

Flight School Supervisor Comments

Students who made negative comments regarding flight school management

Students who made no comments regarding flight school management

Students who made positive comments regarding flight school management

$$
\mathrm{N}=
$$

22

66.7

8

24.2

3

9.1

33

100

Confidence interval: $\pm 6.5 \%$ at the $99 \%$ confidence level 
Table 6: Innovation Stifling

Innovation Stifling: Correlating between Expert Opinions and Student Comments

Kotter (1996)

Managers believe that they are the best.

Managers are arrogant.

Managers become very political.

Tushman \& O'Reilly (2002)

Lack of mutual respect.

Lack of freedom to experiment.

Mangers create barriers to success.

\section{Dundon (2002)}

New ideas not welcome.

Managers fail to empower the customers.

Organization is no longer competitive.
Selected Student Comments

"Supervisors are convinced that they're the best when really they are the worst."

"The supervisors are not willing to help students.

They are self-centered, arrogant, and emotionless."

"Too much favoritism. If you are not in their group they (supervisors) will not pay any attention to you."

"I wish the supervisors acted like they cared about my questions."

"They (supervisors) don't allow any creativity by the flight instructors."

"The supervisors set you up for failure not success."

"I think the supervisor's closed-mindedness hurts the students and their instructor's creative thinking."

"The supervisors don't guide and motivate students. They make the students feel shunned and restricted."

"I got three ratings at another flight school because of the way the supervisors acted around here." 
Figure 1: The Balance between Standardization and Innovation

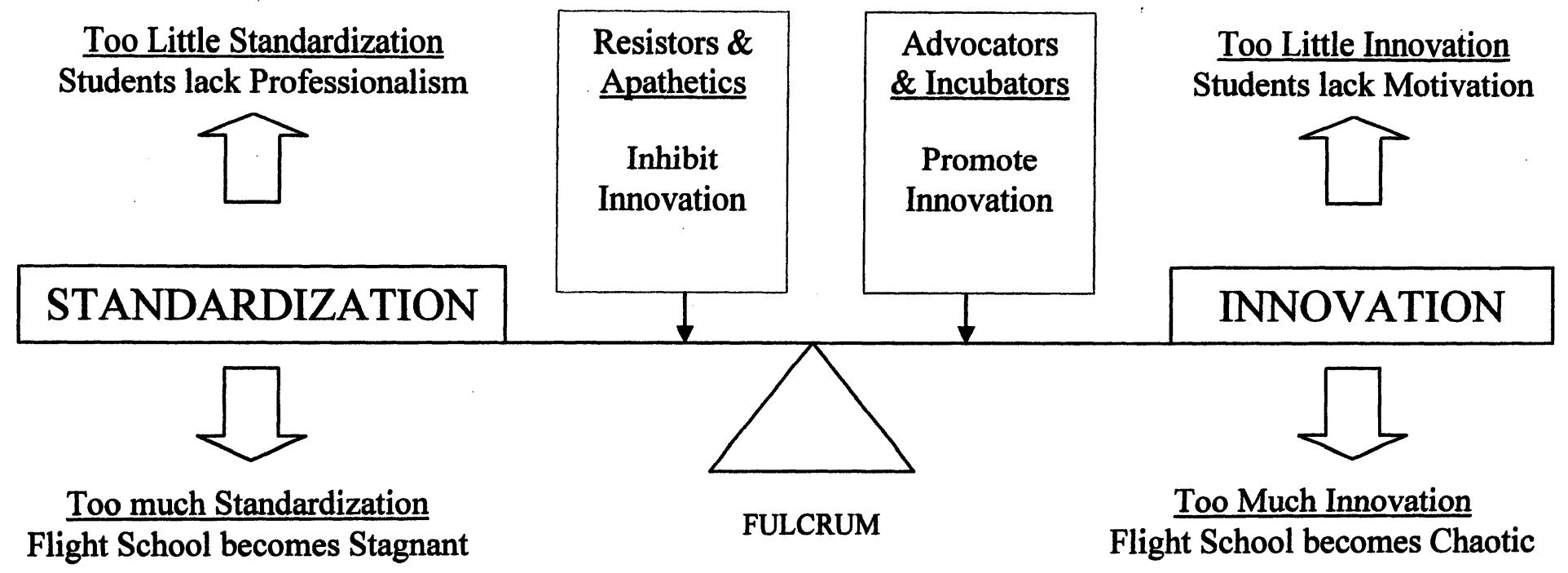

\section{Benefits of a Perfect Balance}

1) Flight school has a positive, innovative learning atmosphere that encourages instructors to train their students above and beyond the minimum standards without sacrificing safety.

2) Flight school has a creative and exciting training environment that motivates students and instructors to achieve their goals without sacrificing professionalism 
